\title{
Variations
}

Variations

Revue internationale de théorie critique

$20 \mid 2017$

Expériences oppositionnelles

\section{Pour Miguel Abensour}

\section{Lucia Sagradini}

\section{OpenEdition}

\section{Journals}

Édition électronique

URL : http://journals.openedition.org/variations/875

DOI : 10.4000 /variations. 875

ISSN : 1968-3960

\section{Éditeur}

Les amis de Variations

Référence électronique

Lucia Sagradini, « Pour Miguel Abensour », Variations [En ligne], 20 | 2017, mis en ligne le 25 avril 2017, consulté le 25 février 2021. URL : http://journals.openedition.org/variations/875 ; DOI : https://doi.org/ 10.4000 /variations.875

Ce document a été généré automatiquement le 25 février 2021.

Les ami•e•s de Variations 


\section{Pour Miguel Abensour}

\section{Lucia Sagradini}

1 Evidement c'est complexe d'écrire de l'endroit d'une relation tumultueuse. Mais il n'est pas rare que le bruit et la fureur soient les compagnons qui marquent des rencontres qui sortent de l'ordinaire. Ces rencontres si difficiles sont pour bien des raisons de l'ordre de l'inoubliable.

2 Si je peux évoquer en quelques lignes, Miguel Abensour, ce sera comme un philosophe et grand interprète. Je pense que lui-même apprécierait ces mots. Il a été et restera un philosophe dans l'esprit d'Husserl. Il ne s'agit pas de chercher les livres que Miguel a écrit, bien qu'il y en ait un nombre certain, mais il s'agit bien plus d'un projet plus vaste et plus large. L'enjeu n'étant pas de faire des objets formatés, dit livres de philosophie, répondant à un espace social et culturel, non, toute la vie intellectuelle de Miguel Abensour s'est entrelacée à celle d'incarner une pensée philosophique qui a croisé lectures, rédactions d'ouvrages, mais aussi travail de transmission, des auteurs de la Théorie critique, dont il a permis la réception en français, mais également par son travail toutes ses années durant en tant que professeur.

Un aussi puissant que timide professeur : timide, car, je ne l'ai jamais vu s'écarter de ses notes, mais puissant, car il a su transmettre, émettre en direction de plusieurs générations d'étudiants, d'élèves. Une pensée, celle du petit. Par son travail de transmission d'auteurs de la Théorie critique, ou de Pierre Clastres, ou encore par son travail axé sur la lutte contre l'antisémitisme, appuyée sur Hannah Arendt ou Theodor W. Adorno.

4 Il tenait bon. Il était souvent seul. Dans un monde désolé. Celui de ceux qui tournaient le dos à des pensées critiques, subversives et émancipatrices. Il portait et soutenait, tel le pont du rêve de Husserl le passage vers certaines idées. Des idées que Miguel Abensour rendait vivantes par son travail d'interprétation et de transmission. Des idées qui nous disaient combien il est essentiel de chercher à porter un regard critique sur le monde, à être les sentinelles qui annoncent l'incendie, à être précautionneux dans la relation à l'altérité et enfin, il donnait du souffle à l'idée que nous pouvions ensemble changer le monde. L'ordre établi. 
5 L'enseignement de Miguel Abensour croisait grande exigence et grandes promesses. Tout son travail et sa vie intellectuelle étaient tournés à donner du souffle. A celui ou celle qui l'écoutait. L'ensemble de ces gestes étaient de ceux qui construisent une philosophie au sens le plus profond : il s'agissait d'une manière de voir et d'agir, et non, le simple jeu des références philologiques. Il était à l'académie ce que peu peuvent prétendre être : il en actualisait la subversivité. Et cela avec un mélange de bonhommie et de discrétion. Parfois de colère aussi.

6 Seul. Il savait que Pascal ne se trompait pas lorsqu'il disait que le plus grand nombre n'a pas de ce fait raison. Il n'a jamais eu d'hésitations. Il n'a jamais abandonné la position. Eclaireur et messager d'une pensée, fragile comme une étincelle. Celle qui porte l'espoir. Messianique?

7 Miguel Abensour s'est éteint, mais j'espère, alors que les temps sont plein d'obscurité, que cette petite lumière qu'il a maintenue allumée, tel un feu, qu'on lui avait transmis et qu'il savait devoir faire passer aux générations suivantes, que tous ceux et toutes celles qui ont eu la chance de recevoir cette étincelle vont à leur tour continuer à la faire vivre. La pensée de l'émancipation. Merci Miguel.

Lucia.

\section{AUTEUR}

\section{LUCIA SAGRADINI}

Professeur d'histoire de l'art et de théories critiques à l'École d'art supérieure des Pyrénées, rédactrice en chef de la revue Variations. 